\title{
EKSISTENSI PENGGUNAAN BAHASA INDONESIA DALAM MEDIA SOSIAL FACEBOOK
}

\section{Oleh:}

\section{Mipa Tiyasmala}

(Universitas Sebelas Maret, minggupahing@student.uns.ac.id)

\begin{abstract}
Abstrak
Media social facebook kini sudah digunakan oleh seluruh lapisan masyarakat mencakup semua umur, baik anak-anak, remaja, dewasa hingga lanjut usia. Fitur yang digunakan dalam media sosial kini juga beragam dan berhubungan dengan profil pengguna. Fenomena kesalahan berbahasa Indonesia dalam media dapat menyebabkan pergeseran makna. Eksistensi bahasa Indonesia yang merupakan jati diri bangsa Indonesia pada era globalisasi sekarang ini, perlu dibina dan dimasyarakatkan oleh setiap warga negara Indonesia. Hal ini diperlukan agar bangsa Indonesia tidak terbawa arus oleh pengaruh dan budaya asing yang tidak sesuai dengan bahasa dan budaya bangsa Indonesia. Pengaruh alat komunikasi yang begitu canggih harus dihadapi dengan memertahankan jati diri bangsa Indonesia, termasuk jati diri bahasa Indonesia. Ini semua menyangkut kedisiplinan berbahasa nasional, dengan mematuhi semua kaidah atau aturan pemakaian bahasa Indonesia. Makalah ini akan menganalisis kesalahan berbahasa dari berbagai usia melalui kajian semantik dengan menggunakan pendekatan referensial. Analisis dilakukan dengan metode studi pustaka yang dikombinasikan dengan metode analisis deskriptif dan dilakukan teknik pengambilan sempel secara acak.
\end{abstract}

\section{Kata Kunci:}

Media sosial, eksistensi bahasa Indonesia, pendekatan referensial 


\begin{abstract}
Social Facebook media has now been used by all levels of society, including all ages, both children, adolescents, adults to the elderly. The features used in social media now also vary and relate to user profiles. The phenomenon of errors in Indonesian in the media can cause a shift in meaning. The existence of Indonesian language which is the identity of the Indonesian nation in the current era of globalization, needs to be fostered and socialized by every Indonesian citizen. This is necessary so that the Indonesian people are not carried away by foreign influences and cultures that are not in accordance with the Indonesian language and culture. The influence of sophisticated communication tools must be faced by maintaining the identity of the Indonesian people, including Indonesian identity. This all concerns national language discipline, by obeying all rules or rules of use of the Indonesian language. This paper will analyze language errors from various ages through semantic studies using a referential approach. The analysis was carried out using the literature study method combined with descriptive analysis methods and random sampling techniques.
\end{abstract}

\title{
Keywords:
}

social media, Indonesian language existence, referential approach

\section{A. PENDAhUlUan}

Media Sosial ialah sarana untuk berkomunikasi sekaligus alat untuk memberi, menerima, dan bertukar informasi. Internet kini seolah menjadi kebutuhan vital yang harus dipenuhi dalam setiap aktivitas yang dilakukan oleh seluruh lapisan masyarakat. Hal tersebut sejalan dengan pendapat Ibrahim (2011: 310) bahwa keberadaan internet secara tidak langsung menghasilkan sebuah generasi yang baru, yaitu generasi next. Generasi ini dipandang menjadi sebuah generasi masa depan yang diasuh dan dibesarkan dalam lingkungan budaya baru media digital yang interaktif, yang berwatak menyendiri (desosialisasi), berkomunikasi secara personal, melek komputer, dibesarkan dengan 
videogames, dan lebih banyak waktu luang untuk mendengarkan radio dan televisi.

Era globalisasi merupakan tantangan bagi bangsa Indonesia untuk dapat mempertahankan diri di tengah-tengah pergaulan antarbangsa yang sangat rumit.untuk itu, bangsa Indonesia harus mempersiapkan diri dengan baik dan penuh perhitungan. Untuk itu, bangsa Indonesia harus mempersiapkan diri dengan baik dan penuh perhitungan. Salah satu yang perlu diperhatikan adalah jati diri bangsa yang diperlihatkan melalui bahasa.

Bahasa Indonesia sebagai bahasa yang masih hidup tidak dapat menghindarkan diri dari tuntutan perkembangan masyarakat pemakainya. Perkembangan bahasa Indonesia telah terjadi sepanjang masa, dapat dibuktikan dengan terdapatnya perbedaan bahasa Indonesia zaman dulu sampai dengan bahasa Indonesia dewasa ini. Perbedaan itu menimbulkan pertentangan antara mereka yang mempertankan bahasa Indonesia dengan generasi muda yang ingin agar bahasa Indnesia dapat berkembang sesuai perkembangan zaman (dalam Nasucha dkk, 2012:3).

$$
\text { Kajian Saddhono (2012) }
$$

berjudul "Pengembangan Buku
Bahasa Indonesia untuk Penutur Asing: Studi Kasus di Universitas Sebelas Maret" (The Development of Indonesian Language Textbooks for Foreign Students:A Case Studies in Sebelas Maret University) memaparkan bahwa dalam upaya meningkatkan kualitas pembelajaran maka diperlukan buku teks. Buku teks ini bertujuan agar pembelajaran dapat dilakukan sesuai dengan kompetensi yang diharapkan. Maka dari itu, perlu mempelajari sumbersumber referensi yang selaras dengan topik kajian.

Kejelasan makna dalam kalimat dipengaruhi dengan adanya pemilihan kata yang baik dan tepat sehingga setiap kata dapat dipahami maknanya. Makna kata dibuat setepat mungkin untuk menghindari kesalahpahaman terhadap makna yang ada pada pemakaian kata. Setiap kata memiliki makna denotasi dan konotasi. Makna denotasi (dalam Chaer, 2009:66) sering disebut dengan makna sebenarnya, sedangkan makna konotasi sering disebut makna tidak sebenarnya. Makna denotasi sering juga disebut dengan makna denotasional, makna konseptual, atau makna kognitif karena dilihat dari sudut yang lain. Makna konotasi juga disebut makna tidak sebenarnya 
Pendekatan

referensial

mengaitkan makna dengan masalah nilai serta proses berpikir manusa dalam memahami realitas lewat bahasa secara benar. Pada tingkatan yang paling sederhana, kata itu hadir karena adanya dunia luar. Dengan demikian, pada tingkat awal terdapat hubungan yang penting antara makna dan dunia luar. Oleh karena itu, pendekatan referensial pada umumnya digunakan pada awal kajian semantik (dalam Suwandi, 2011: 69-70).

Penulisan bahasa Indonesia yang tidak sesuai dengan kaidah kebahasaan akan menyebabkan pergeseran makna. Pergeseran makna menurut Parera (2004:107) adalah gejala perluasan, penyempitan, pengonotasian (konotasi), penyintestesiaan (sinestesia), dan pengasosian sebuah makna kata yang masih hidup dalam satu medan makna.

Beberapa faktor yang menjadi penyebab terjadinya kesalahan pemakaian bahasa Indonesia tersebut juga sesuai dengan penelitian yang dilakukan oleh Jalal (2012). Dalam penelitian yang telah dilakukannya, disebutkan bahwa terjadinya kesalahan pemakaian bahasa Indonesia disebabkan oleh faktor di antaranya, adanya keterbatasan dalam penyampaian materi pemakaian bahasa yang baik dan benar, serta adanya sikap kurang teliti dan kurang peduli dengan pemakaian kaidah-kaidah bahasa dalam tulisan, sehingga hasil penelitian ini sesuai dengan penelitian yang telah dilakukan oleh Jalal (2012).

Pemakaian bahasa Indonesia sebagai bahasa kedua bagi penutur bahasa asing pun tidak lepas dari kesalahan. Penelitian Saddhono, 2012 dalam Kajian Sosiolinguistik Pemakaian Bahasa Mahasiswa Asing dalam Pembelajaran Bahasa Indonesia Untuk Penutur Asing (BIPA) di Universitas Sebelas Maret menegaskan bahwa semakin tinggi jumlah kesalahan, makin rendah tingkat pencapaian tujuan pembelajaran bahasanya. Oleh karena itu, tentunya harus ada upaya menekan sekecil-kecilnya kesalahan berbahasa yang dilakukan.

$$
\text { Bila dikaitkan dengan }
$$
pendidikan di Indonesia, bahasa Indonesia memiliki peranan sentral dalam perkembangan intelektual, sosial, dan emosional peserta didik dan merupakan penunjang keberhasilan dalam mempelajari semua bidang studi, di samping bahasa daerah yang peranannya tidak dapat diabaikan. Pengajar 
bahasa Indonesia sudah selayaknya menyadari benar akan pentingnya aspek budaya dan bahasa daerah serta bahasa sebagai alat berpikir, pengajaran bahasa Indonesia diarahkan pula pada pengembangan berpikir. Pembelajaran berbasis teks selalu mempertimbangkan persoalan konteks, baik konteks sistuasi maupun konteks budaya. Teks serbagai realiasasi atau wujud perilaku verbal manusia selalu dilatarbelakangi oleh konteks, yaitru konteks situasi dan konteks budaya (Zamzani, 2014).

Kedudukan dan fungsi bahasa menurut Depdiknas dalam Pelatihan Nasional Dosen Pengembangan kepribadian di Perguruan Tinggi berpendapat bahwa bahasa Indonesia sebagai: a) Bahasa Nasional; b) Lambang Kebanggaan Nasional; c) Lambang Identitas Nasional; d) Alat Pemersatu Berbagai Suku Bangsa; e) Alat Perhubungan Antardaerah dan Antarbudaya; f) Bahasa Negara; g) Bahasa Kenegaraan; h) Bahasa Pengantar dalam Dunia Pendidikan; i) Alat Perhubungan di Tingkat Nasional untuk Kepentingan Pembangunan dan Pemerintahan; j) Alat Pengembangan Kebudayaan, IImu Pengetahuan, dan Teknologi Indonesia (dalam Rohmadi dkk, 2008: 5-7).
Bahasa Indonesia telah digunakan sejak lama oleh beragam komunitas di berbagai pulau. Kondisi itulah yang menyebabkan munculnya variasi atau ragam bahasa Indonesia. Varian menurut pemakai disebut dialek, sedangkan varian menurut pemakaian disebut ragam bahasa. Ragam bahasa adalah variasi bahasa yng dibebkan topik, hubungan pembicara, lawan bicara, dan orang yang dibicarakan, serta karena perbedaan media pembicaraan (dalam Ismawati, 2012:9).

Bahasa Indonesia dalam perguruan tinggi biasanya dipakai saat mahasiswa yang memiliki perbedaan daerah saling berkomunikasi. Dalam masyarakat luas ataupun lingkungan non akademik penggunaan bahasa Indonesia biasanya digunakan saat acara rapat resmi dalam di daerahdaerah atau jika bertemu dengan orang yang belum dikenal sebelumnya. Walaupun demikian penggunaan bahasa Indonesia di media social khususnya facebook sering salah kaprah dan bercampur dengan bahasa daerah atau bahasa asing. 


\section{B. METODE PENELITIAN}

Penelitian ini menggunakan metode studi pustaka atau sering dikenal dengan istilah Literature Review. Manfaat metode ini ialah menghemat waktu dan juga menghindari kesalahan-kesalahan yang pernah dilakukan oleh orang lain. Selain itu juga meneruskan apa yang penelitian sebelumnya telah dicapai sehingga dengan adanya studi pustaka ini, penelitian yang akan dilakukan dapat membangun di atas landasan (platform) dari pengetahuan atau ide yang sudah ada. Model analisis deskrptif digunakan sebagai metode pendukung dalam penelitian ini untuk menganalisis kesalahan terhadap kaidah kebahasaan. Teknik pengambilan sampel dalam penelitian ini menggunakan cluster random sampling.

\section{HASIL DAN PEMBAHASAN}

Kesalahan berbahasa yang terjadi atau dilakukan oleh siswa dalam suatu proses belajar mengajar mengimplikasikan tujuan pengajaran belum tercapai secara maksimal. Semakin tinggi kuantitas kesalahan berbahasa, semakin sedikit tujuan pengajaran bahasa yang tercapai. Kesalahan berbahasa yang dilakukan oleh siswa harus dikurangi sampai ke
Kajian ini termasuk dalam penelitian sosiolinguistik yang mengkaji hubungan antara bahasa dan masyarakat penuturnya. Soepomo Poedjosoedarmo (tt:20) menyatakan bahwa penelitian sosiolinguistik pada dasarnya adalah penelitian kontekstual. Penelitian kontekstual adalah penelitian mengenai wujud tuturan (bahasa) dengan memperhatikan konteks sosial yang menyertai terjadinya suatu tuturan. Dalam analisis data akan diperhitungkan konteks social yang berupa komponen tutur, yaitu (1) penutur atau pembicara, (2) mitra tutur atau lawan tutur, (3) situasi tutur atau situasi bicara, (4) tujuan tuturan, dan (5) hal yang dituturkan (Sudaryanto, 1995:38).

batas minimal, bahkan dihilangkan sama sekali. Hal ini dapat tercapai jika guru pengajar bahasa telah mengkaji secara mendalam segala aspek seluk beluk kesalahan berbahasa itu (dalam Setyawati, 2013 :15).

Sejalan dengan pernyataa diatas, Ariningsih (2012) menegaskan bahwa dengan tidak memperhatikan 
struktur bahasa yang digunakan serta tanda baca yang dipakai, unsur kohesi maupun koherensi dalam suatu paragraf menjadi tidak terpenuhi. Kohesi dan koherensi yang kurang membuat yang ada tidak mampu menyampaikan gagasan penulis dengan sempurna.

Era digital yang menuntut penguasaan teknologi dan bahasa asing pada berbagai bidang kehidupan saat ini makin meminggirkan posisi bahasa Indonesia. Seharusnya, posisi ini tidak berarti bahwa bahasa Indonesia tidak mampu bersaing dengan bahasa lain di dunia, tetapi lebih pada sikap bangsa Indonesia sebagai pengguna bahasa Indonesia yang cenderung menunjukkan sikap negatif. Jika bangsa Indonesia sebagai pemilik dan pemakai bahasa Indonesia terus bersikap negatif terhadap bahasa nasionalnya, bahasa Indonesia akan berkembang secara kacau dan tak pernah bahasa ini menjadi bahasa yang mantap (Marsudi, 2009).

Tabel 1

\begin{tabular}{|c|c|c|c|}
\hline \multicolumn{4}{|c|}{ Pengguna Media Sosial } \\
\hline Anak & Remaja & Dewasa & Tua \\
\hline 3 & 8 & 5 & 4 \\
\hline
\end{tabular}

Berdasarkan hasil survei dilapangan dengan mengambil sempel sebanyak 20 pengguna facebook yang terdiri dari 5 pengguna pada setiap golongannya maka diperoleh data kesalahan penggunaan bahasa Indonesia di media sosial seperti table diatas.

Dapat dilihat pada tabel bahwa kesalahan penggunaan bahasa Indonesia tertinggi diduduki oleh golongan remaja. Hal tersebut dikarenakan minimnya pemahaman penggunaan bahasa Indonesia secara baik, benar, dan santun.

Tabel 2

\begin{tabular}{|l|lr|}
\hline Usia & J awab \\
\hline Anak & $\begin{array}{l}\text { Aktivitas yang sedang } \\
\text { dilakukan }\end{array}$ \\
\hline Remaja & Penggambaran isi hati \\
\hline Dewasa & $\begin{array}{l}\text { Pemaparan materi } \\
\text { mengenai keadaan } \\
\text { lingkungan sekitar }\end{array}$ \\
\hline Tua & $\begin{array}{l}\text { Menceritakan risah } \\
\text { inspiratif r }\end{array}$ \\
\hline
\end{tabular}

Bahasa menurut Rahardi (2010:2) merupakan cermin (mirror) bagi keberadaan masyarakatnya. Itulah sebabnya sering dikatakan pula bahwa bahasa hamper pasti menunjukkan bangsanya. Pada bangsa yang maju, bahasanya juga maju, tertata, dan bermartabat. Jika hal-ihwal kemajuan itu dikaitkan dengan dinamika dan martabat bahasa, dapat dikatakan pula bahwa bangsa yang modern hamper pasti 
memiliki dinamika dan martabat bahasa yang maju dan modern pula.

Apabila dianalisis lebih mendalam mengenai kajian semantik, kesalahan penggunaan bahasa Indonesia menakibatkan pergeseran makna. Jika dilihat dari sudut pandang pendekatan referensial kalimat tanya "apa yang sedang anda pikirkan?" maka kecenderungan menjawab dapat dilihat pada tabel 2 . Konteks bahasa dalam hal ini mengarah pada konteks pertuturan atau konteks situasi, yang dapat mencakup aspek identitas partisipan, waktu dan tempat peristiwa komunikasi, topik pertuturan, dan tujuan pertuturan

Tidak dapat dipungkiri bahwa umur seseorang akan membedakan cara berbicara. Misalnya perbedaan kata yang digunakan. Seorang remaja tentu tidak akan berbicara seperti seorang yang berusia 5 tahun. Ungkapan, pilihan kata, dan konstruksi itu dipilih oleh penutur dari generasi yang berberbeda. Selain itu, ada bagian bahasa, lebih-lebih pada tataran leksikal dan sintaksis, yang dirasakan berbeda oleh para penutur yang "kekinian" dengan yang "kuno".

Kalimat tanya "apa yang sedang anda pikirkan?" memiliki makna bahwa ingin mengetahui apa yang ada dalam pikiran seseorang.
Akan tetapi, dari sudut pandang lain bermaksud untuk menanyakan apa isi hati seseorang. Kalimat tanya tersebut dapat memberikan informasi yang berbeda. Hal tersebut dikarenakan memang pengaruh usia dapat mempengaruhi pola pikir seseorang. Representasi suatu bahasa pada hakikatnya berupa kegiatan pemakaian bahasa itu sendiri oleh komunitasnya dalam berbagai keperluan. Nilai bahasa terletak pada makna yang disimbolkan oleh suatu bahasa.

Bahasa sebagai wahana dan produk budaya. Kegiatan berbahasa tidak dapat dilepaskan dari kegiatan berpikir, sebagai bagian dari budaya. Oleh karena itu, bahasa selain memiliki fungsi utama sebagai alat komunikasi, terdapat satu fungsi bahasa yang utama lagi yaitu sebagai sarana bernalar atau berpikir. Pengajaran bahasa memiliki peranan penting di dalam upaya merealisasikan fungsi ini. Hal itu didasari oleh kenyataan adanya kaitan yang erat antara sistem budaya, berbahasa, dan berpikir sebagai bagian dari budaya. Keunikan manusia bukan sekedar ditunjukkan oleh kemampuan berpikir malainkan oleh kemampuan berbahasa. 
Fenomena pemakaian kata ganti persona juga pernah dikaji Saddhono (2006: 1-5) yang membahas tentang pemakaian bahasa etnik madura di Kota Surakarta. Pemakalain kata 'aku' dan 'saya' dapat diperbandingkan dengan pemakaian kata 'kaula' dalam bahasa Madura atau Jawa yang setara dengan kata 'saya'. Dalam bahasa Jawa kata 'kaula' berarti rakyat, orang biasa, hamba dan merupakan lawan kata dari 'gusti' yang berarti 'tuan'. Masyarakat Jawa dan Madura menggunakan kata 'kaula' (bahasa Jawa dibaca kaulo atau kulo; bahasa Madura dibaca kauleh atau kuleh) untuk menunjukkan status yang lebih rendah dari mitra tuturnya. Pemakaian ini sama dengan penggunaan kata 'saya' dalam bahasa Melayu yang penggunaannya berbeda dengan kata 'aku'.

Berdasarkan hasil penelitian menegaskan bahwa banyaknya kalanganvremaja menggunakan bahasa gaul adalah akibat dari perkembangan zamanvyang kian mengalami kemajuan baik dari dunia pendidikan sampai teknologi. Gejala bahasa yang dapat menghambat pertumbuhan dan perkembangan bahasa Indonesia dianggap sebagai penyimpangan terhadap bahasa. Adapun kurangnya kesadaran untuk mencintai bahasa di negeri sendiri berdampak pada lunturnya pemakaian bahasa Indonesia dalam pendidikan dan pengajaran ataupun dalam kehidupan sosial masyarakat. Apalagi dengan maraknya dunia kalangan artis menggunakan bahasa gaul di media social (dalam Rahayu, 2015).

Eksistensi bahasa Indonesia yang merupakan jati diri bangsa Indonesia pada era globalisasi sekarang ini, perlu dibina dan dimasyarakatkan oleh setiap warga negara Indonesia. Hal ini diperlukan agar bangsa Indonesia tidak terbawa arus oleh pengaruh dan budaya asing yang tidak sesuai dengan bahasa dan budaya bangsa Indonesia. Pengaruh alat komunikasi yang begitu canggih harus dihadapi dengan memertahankan jati diri bangsa Indonesia, termasuk jati diri bahasa Indonesia. Ini semua menyangkut kedisiplinan berbahasa nasional, dengan mematuhi semua kaidah atau aturan pemakaian bahasa Indonesia. 


\section{KESIMPULAN}

Media sosial facebook merupakan sarana untuk menjunjung ekisistensi bahasa Indonesia. Berdasarkan pemaparan dimuka, dapat ditarik kesimpulan bahwa kesalahan penggunaan bahasa Indonesia mayoritas dilakukan oleh kalangan remaja. Terjadinya kesalahan dalam berbahasa diakibatkan karena berbagai faktor. Untuk menjaga eksistensi bahasa Indonesia dapat dilakukan dengan

\section{DAFTAR PUSTAKA}

Ariningsih, Nur Endah. 2012. "Analisis Kesalahan Berbahasa Indonesia dalam Karangan Eksposisi Siswa Sekolah Menengah Atas". BASASTRA, Jurnal Penelitian Bahasa, Sastra Indonesia, dan Pengajarannya, Volume 1 Nomor 1, Desember 2012, 130-141.

Chaer, Abdul. 2009. Pengantar Semantik Bahasa Indonesia. Jakarta: Rineka Cipta

Dahlan, M. Alwi. 2000. Bahasa Indonesia dalam Era Globalisasi. "Bahasa Indonesia dalam Kehidupan Bermasyarakat, Berbangsa, dan Bernegara: Perannya Menghadapi Globalisasi. Jakarta: Pusat Pembinaan dan Pengembangan Bahasa Departemen Pendidikan Nasional. cara berbahasa dengan baik, benar, dan santun. Berbagai kesalahan dalam berbahasa Indonesia dapat kita kurangi bahkan dapat kita hapus dengan cara giat berlatih menguasai kosakata dan aturan bahasa Indonesia yang baik. Mulai dari membaca buku yang memiliki bahasa baik dan membiasakan berbicara dengan bahasa Indonesia sesuai kaidah dalam acara-acara resmi.

Ibrahim \& Subandy, I. 2011. Kritik Budaya Komunikasi. Yogyakarta: Jalasutra

Ismawati, E. 2012. Bahasa Indonesia untuk Penulisan Karya Ilmiah. Yogyakarta: Penerbit Ombak

Jalal, Moch. 2012. "P roblematika Kesalahan Bahasa Pada Penulisan Skripsi Mahasiswa Universitas Airlangga". Mozaik: J urnal IImu Humaniora, Volume 12 Nomor 2, Juli-Desember 2012, 92-209.

Marsudi. 2009. Jati Diri Bahasa Indonesia di Era Globalisasi Teknologi Informasi. dalam Jurnal Sosial Humaniora Vol. 2, No. 2, November 2009.

Nasucha, dkk. 2012. Bahasa Indonesia untuk Penulisan Karya Tulis 
Ilmiah.Yogyakarta: Media Perkasa.

Parera, D J. 2004. Teori Semantik. Jakarta: Penerbit Erlangga

Rahardi, K. 2010. Bahasa Indonesia untuk Perguruan Tinggi. Jakarta: Penerbit Erlangga

Rahayu, A P. 2015. Menumbuhkan Bahasa Indonesia yang Baik dan Benar dalam Pendidikan dan Pengajaran. dalam Jurnal Paradigma Vol. 2, No. 1, November 2015

Rohmadi, dkk. 2008. Teori dan Aplikasi: Bahasa Indonesia di Perguruan Tinggi. Surakarta: UNS Press

Saddhono, Kundharu. 2006. "Bahasa Etnik Madura di Lingkungan Sosial: Kajian Sosiolinguitik di Kota Surakarta" dalam Jurnal Kajian Linguistik dan Sastra Vol. 18, No. 34 Tahun 2006, hal. 115.

Saddhono, Kundharu. 2012. "Pengembangan Buku Bahasa Indonesia untuk Penutur Asing: Studi Kasus di Universitas Sebelas Maret (The Development of Indonesian Language Textbooks for Foreign Students:A Case Studies in Sebelas Maret University)" dalam The 3rd AISOFOLL di Jakarta 30 Oktober -1 November 2012 oleh SEAMEO QITEP.
Saddhono, Kundharu. 2012. "Kajian Sosiolinguistik Pemakaian Bahasa Mahasiswa Asing dalam Pembelajaran Bahasa Indonesia Untuk Penutur Asing (BIPA) di Universitas Sebelas Maret" dalam Jurnal Kajian Linguistik dan Sastra Vol. 24, No. 2 Tahun 2012, hal. 176-186.

Setyawati. Analisis Kesalahan Berbahasa Indonesia (Surakarta: Yuma Pustaka, 2013)

Sudaryanto. 1994. "Metode dan Aneka Teknik Pengumpulan Data dalam Rangka Linguistik: Prinsip-prinsip dan Konsep-konsep Dasar" dalam Bacaan Linguistik. Yogyakarta: Masyarakat Linguistik Indonesia.

Suwandi, S.2011. Semantik Pengantar Kajian Makna. Yogyakarta: Media Perkasa

Ullman, S. 2012. Pengantar Semantik.Yogyakarta: Pustaka Pelajar

Zamzani. 2014. Eksistensi Bahasa Indonesia dalam Pendidikan Berbasis Keragaman Budaya. dalam Jurnal Dialektika Vol.1, No.2, Desember 2014. 